\title{
AN INTEGRATIVE APPROACH FOR VO PLANNING AND LAUNCHING
}

Ricardo Camacho, David Guerra, Nathalie Galeano, Arturo Molina

DIA, Center for Innovation in Design and Technology, ITESM Campus Monterrey 100788106@itesm.mx, david.guerra@itesm.mx, ngaleano@itesm.mx, armolina@itesm.mx

$M E X I C O$

\begin{abstract}
Virtual organizations (VO) have been rapidly growing within collaborative business environment. However, there is need to develop work related to VO planning and launching. This paper proposes a reference model to plan and launch VOs. The reference has a three dimensional structure. The first dimension is related with VO life cycle. Second dimension shows VO modelling views supported by UML. Third dimension presents VO knowledge management structure, VO knowledge assets are structured in procedural, organizational and operational domains, which enable knowledge creation and sharing within virtual organizations. $A$ case study is presented in order to demonstrate reference model us in VO planning and launching.
\end{abstract}

\section{INTRODUCTION}

In an era where rapid changes have been guided by trends such as mass customization, agility, globalization and an increasing demand for extended products and services, the competitive focus of organizations is shifting to cooperation schemas in many different ways (Saabeel et al, 2002). VOs are a new organizational scheme that requires high levels of agility in order to achieve a competitive advantage when a business opportunity is identified. Due to VO characteristics it is important to establish a systematic approach for VO planning and launching.

The aim of this paper is twofold: to present a novel reference model as a mechanism for VO planning and launching using a systematic approach and to describe how this reference model is implemented in a study case.

\section{BACKGROUND: VO PLANNING AND LAUNCHING}

VO is a term being used to describe how different organizations come together to explore business opportunities, and collaborating on a temporary basis (Katzy and Obozinky, 1999). Several definitions have been explored for Virtual Organization, this work uses the following definition: "VO's are temporary alliances of organizations that come together to share skills or core competencies and resources in order to better respond to business opportunities and produce value-added 
services and products, and whose cooperation is supported by computer networks". (Camarinha-matos and Afsarmanesh, 2004)

One of the challenges in VO environment is to setup fast and efficient VOs. Tølle (2004) established that, the ability to create VE (VE is a particular case of VO) composed of the best competencies available, should be linked to a competitive setup, otherwise the virtual enterprise vanishes. This phenomenon is also presented in VO's. Thus, references, methods and tools that support and enhance the process of VO creation, especially in planning and launching stages are required.

Enterprise Reference Architectures helps in the process of VO planning and launching by providing an integrated approach for VO creation. The Generalized Enterprise Reference Architecture and Methodology (GERAM) framework is used in this work to support some elements of the Reference Model presented. GERAM is the major outcome of IFAC Task Force on Enterprise Integration (Bernus et al, 2003), which has become the basis of an international standard. "The purpose of GERAM is to serve as a reference for the whole community concerned with the area of enterprise integration providing definitions of the terminology, a consistent modelling environment, a detailed methodology, promoting good engineering practice for building reusable, tested, and standard models, and providing a unifying perspective for products, processes, management, enterprise development, and strategic management" (Vernadat, 1996).

Together with the need of having references and models that support the VO creation, VO knowledge management and information transfer among partners is an important issue to consider. The success of any VO will only come through optimizing the learning process of the VO (Jackson, 1999). In addition, it is important to mention that some authors have explored around the knowledge concept trying to obtain more understanding about this concept (Guerra, 2004).

Identification of types of knowledge helps for the analysis of knowledge management. According to Leonard and Sensiper (1998) knowledge types can be represented in a knowledge spectrum (See figure 1), "at one extreme it is almost completely tacit, that is, semiconscious and unconscious knowledge held in peoples' heads and bodies. At the other end of the spectrum, knowledge is almost completely explicit, or codified, structured, and accessible to people other than the individuals originating it. Most knowledge, of course, exists in between the extremes". Tacit knowledge consists of personal relationships, practical experience and shared values. Explicit knowledge is a formal and systematic type of knowledge consisting of basic facts and storable document sets (Guerra, 2004).

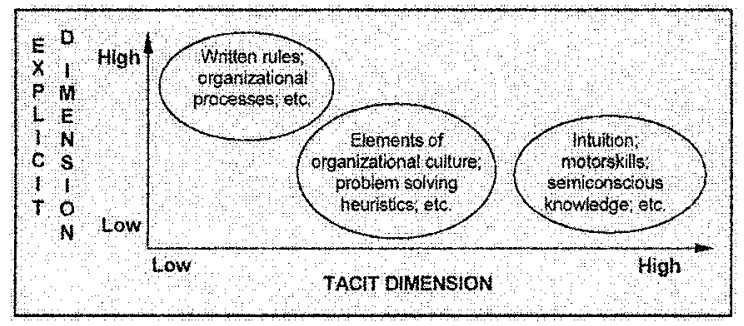

Figure 1.- Knowledge spectrum (Leonard and Sensiper, 1998) 


\section{REFERENCE MODEL FOR VO PLANNING AND LAUNCHING}

The purpose of the reference model presented in this work is to provide guidelines for VO planning and launching activities. The reference model integrates the elements involved in VO creation in a three dimensional structure. First dimension represents the VO life cycle (Creation, Operation \& Evolution and Dissolution). In this reference model only VO creation stage is included, this stage is divided into two sub-stages: Planning and Launching. Second dimension consists of four modelling views. These views provide the basis for the creation of a multidimensional model in order to represent the interactions of the VO elements involved in creation process. Third dimension establishes how the knowledge, generated during the process of VO planning and launching, is captured, shared and exploited. Three knowledge domains are included that act as filters to structure planning and launching knowledge.

\subsection{First dimension: VO planning and launching within VO lifecycle}

This dimension has a direct relationship with VO lifecycle (Creation, Operation/Evolution \& Dissolution); within this dimension five main activities are included, the activities are: (1) Analysis of Business Opportunity, (2) Partners selection, (4) High WBS (Work breakdown structure) and (5) VO Setup. Methods, tools and models are customized according to the characteristics of the VO for each activity. It is important to select suitable methods and tools that support this dimension, some example of IT tools are: (1) Web-enabled project management tools, (2) Workflows, (3) simulation tools and Matchmaking engine.

\subsection{Second dimension: VO modelling.}

This dimension is composed by four modelling views based on GERAM, these views support the creation of a multidimensional model (VO model). The modelling views are: 1) Resource: This view represents all the resources (Human, Technological, etc.) employed by the processes developed by the Virtual Organization in order to achieve their objective. 2) Organization: Represents the responsibilities, authorities and relationships of all the entities involved in the Virtual Organization. 3) Functional: This view represents the behaviour of the entities involved in the processes developed in the life cycle. 4) Information: This view represents the information and knowledge structure among the entities involved in the Virtual Organization, and the relationships among these entities.

To enable the creation of a VO model an enterprise modelling language is needed. In this work Unified Modelling Language (UML) is the language that will support the creation of the models for each modelling view. Examples of IT tools that enable the creation of this model are: ARIS Toolset, UML and IDEF modelling tools, among others. 


\subsection{Third dimension: VO knowledge management.}

Third dimension establishes the mechanism that supports knowledge management during VO planning and launching, to enable knowledge capturing and sharing among VO partners. Three knowledge domains are defined based on the work of Fischer and Rehm (2004). The purpose of the knowledge domains is to act as filters for the knowledge generated during VO planning and launching. Through the action of these domains it will be possible to display in a structured way the knowledge among VO partners, here is a brief description of the three domains:

Organizational Knowledge: This domain includes all knowledge related with VO structure, members profile, roles, competencies, authorities and available resources.

Procedural Knowledge: This domain includes knowledge which represents the way the VO's work; this can be procedures, member's responsibilities, business processes, etc.

Operational Knowledge: This includes knowledge related with the status of the activities been developed within VO, can be Gantt Charts, quality inspections reports, etc.

To enable knowledge capturing and sharing among members it is important to translate knowledge domains characteristics into specific IT tools; examples of these tools are Object-Oriented Databases and Ontology Managers.

\subsection{Reference Model Relationships among dimensions}

Important elements in the reference model are the relations that exist between the dimensions. Figure 2 depicts how planning stage activities (First dimension) are developed and how knowledge domains (Third dimension) capture the knowledge generated during these activities. For facilitate and enable knowledge exchange among VO members it is important to create a knowledge repository based on the knowledge domains mentioned in section 3.3 , the knowledge repository should be able to allow distributed access to the VO members involved in planning activities. This knowledge repository will capture and share the knowledge generated during planning and launching activities. The relationship between these two dimensions is guided by planning activities because the knowledge to be captured in the domains is generated during the activities of the first dimension. 


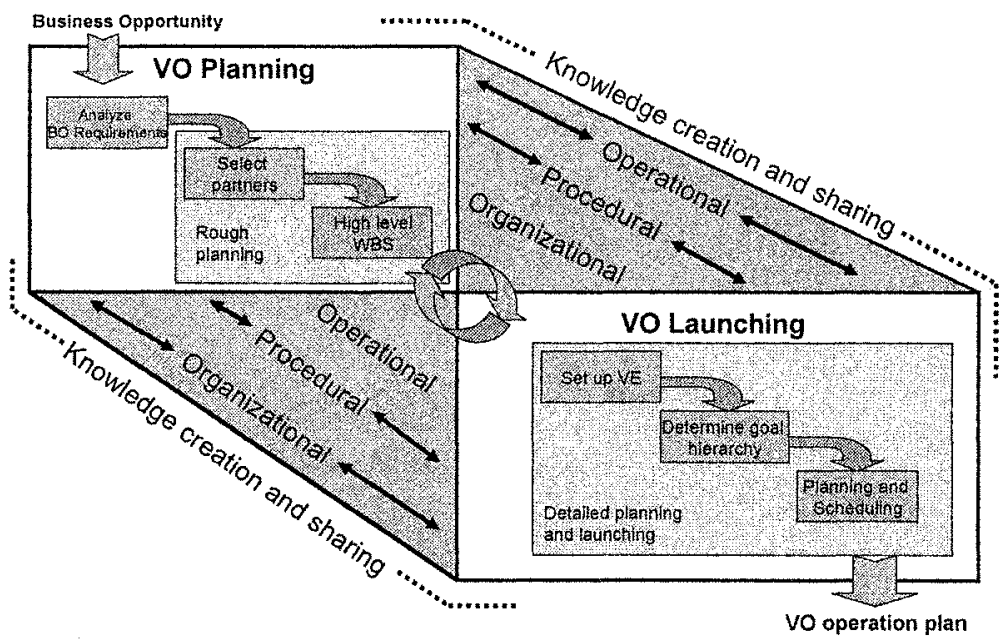

Figure 2. - Description of the relationships between reference model dimensions

The relationship between first dimension (Planning and launching activities) and second dimension (modelling views) are based on the models required for each activity. Each activity required in VO planning and launching should be accompanied by a set of models according to the four modelling view (information, organization, function and resource). The purpose of these models is to represent the interaction of VO members and define the resources required to develop planning and launching activities.

Third and Second dimensions have a relationship based on the UML diagrams used to build the VO model, this diagrams are related to the knowledge domains. Knowledge domains support VO modelling by providing diagrams developed during past VO models that can be used in order to enhance the creation of new models.

\section{STUDY CASE: VO PLANING AND LAUNCHING IN IECOS COMPANY}

IECOS (www.iecos.com) is a broker company located in Monterrey, México who has three main competencies: Supply Services, Engineering Services and Construction Services. The study case analyzed on this work is using IECOS Supply Services (IECOS-SS) division. IECOS-SS identified a Business Opportunity related with the fabrication of Aerospace Maintenance Tooling (inspection equipment). This product has different components. The components are mainly machined and plastic injection parts.

Following the description of the reference model for VO planning and launching is described in each dimension according to IECOS characteristics. First dimension was developed based on VEM-Virtual Enterprise Methodology (TØ1le, 2004) as a basis for VO planning and launching. This methodology was adapted according to 
IECOS particular characteristics (See table 1), including 4 main stages: (1) Analysis of Business Opportunity, (2) Partners selection, (3) High WBS and (4) VO setup. A detailed description of each activity is presented in table 1.

Table 1. - IECOS Study Case planning and launching methodology stages.

\begin{tabular}{|c|c|c|}
\hline $\begin{array}{l}\text { Methodology } \\
\text { Stages }\end{array}$ & Vo Specific Sub-Stages & Description. \\
\hline \multirow{3}{*}{$\begin{array}{l}\text { Analysis of } \\
\text { Business } \\
\text { Opportunity }\end{array}$} & $\begin{array}{l}\text { Analysis of Cluster } \\
\text { Members capabilities }\end{array}$ & $\begin{array}{l}\text { Seven Virtual Industry Clusters were analyzed and two } \\
\text { of them where identified as possible sources of suppliers }\end{array}$ \\
\hline & Drawings analysis & $\begin{array}{l}\text { All product related drawings were analyzed and } \\
\text { comments about product characteristics were captured }\end{array}$ \\
\hline & $\begin{array}{l}\text { Identification of required } \\
\text { processes }\end{array}$ & $\begin{array}{l}\text { Based on product characteristics, the required } \\
\text { manufacturing processes were defined }\end{array}$ \\
\hline $\begin{array}{l}\text { Partners } \\
\text { selection }\end{array}$ & $\begin{array}{l}\text { Evaluation and selection } \\
\text { of members competencies }\end{array}$ & $\begin{array}{l}\text { Two clusters were analyzed, within these cluster two } \\
\text { members were selected according its capabilities }\end{array}$ \\
\hline High WBS & $\begin{array}{l}\text { Product Work Breakdown } \\
\text { Structure }\end{array}$ & $\begin{array}{l}\text { Using a project management tool, the product was break } \\
\text { down into specific needs that VO members should } \\
\text { accomplish. }\end{array}$ \\
\hline \multirow[t]{2}{*}{ VO Setup } & VO Structure Definition & $\begin{array}{l}\text { During this stage four activities were developed: } \\
\text { Members role definition, quotation process, Definition of } \\
\text { contractual issues and operating rules. }\end{array}$ \\
\hline & VO Project Definition & $\begin{array}{l}\text { This stage established the Vo project plan, to develop } \\
\text { this plan several activities were developed: Project } \\
\text { strategy definition, implementation plan development, } \\
\text { defintion of project schedule and project plan } \\
\text { development among VO members }\end{array}$ \\
\hline
\end{tabular}

A VO model was created in order to represent the interaction of VO elements. To create this model four UML diagrams were developed: 1) Use case diagrams to represent organizational view, the use case diagram was used because for this study case it was required to identify how the VO members are involved in VO planning and launching activities; 2) Activity diagrams for functional view, representing how planning and launching activities were developed and which members was responsible to develop an specific activity; 3) Class diagrams to represent resource views of all members involved in the VO; 4) Sequence diagrams for information view that represent information exchange among members. Through the integration of these UML diagrams was possible to build a multidimensional model (VO model) which represents how VO members are involved in planning and launching stages. The type of diagrams used depends of the modelling requirements defined for specific VOs. Figure 3 shows how UML diagrams were integrated in IECOS Aerospace Product VO model. 


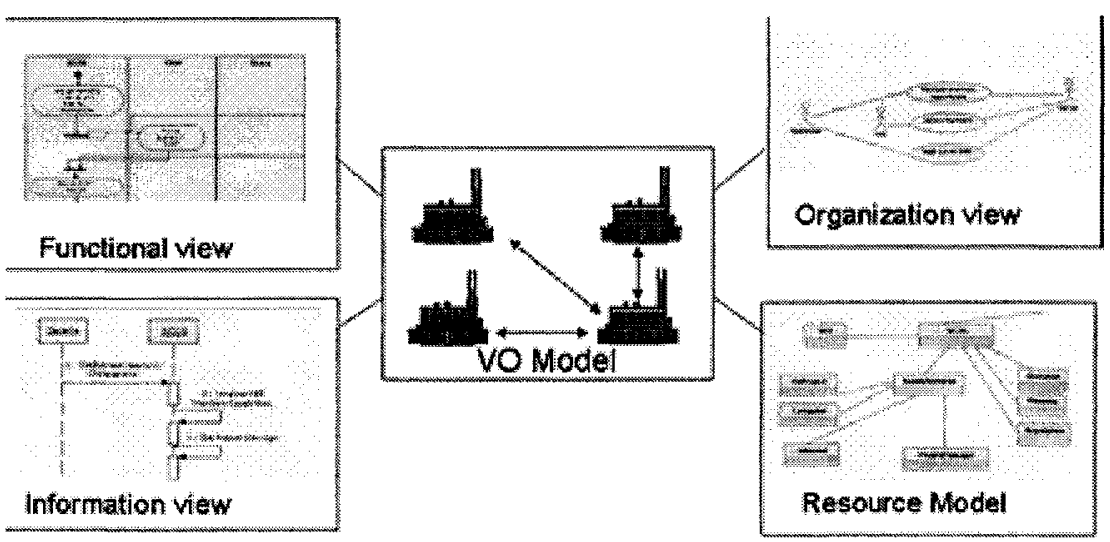

Figure 3. - UML diagrams within VO model

Regarding to the third dimension, to enable knowledge capturing and sharing among VO members, a knowledge repository was created using an object oriented database. The architecture of the database was based on the knowledge domains mentioned in section 3.3. General Knowledge Base software (www.baltsoft.com) was used to create the knowledge repository. The database was set up for capturing and sharing knowledge among VO members. IECOS was the administrator of the knowledge repository structure and access privileges of VO members. Through this database it is possible to structure the knowledge generated during VO creation process; VO members involved in VO planning and launching activities were interacting with the knowledge repository through uploading and downloading the knowledge generated during the development of VEM activities.

The outputs after VO model implementation were: 1) A detailed VO project plan deployed among VO members in order to develop specific activities related with the product; 2) A VO knowledge repository which can be used during operation and dissolution stages; 3) A VO model that clearly represents how all VO entities are involved in VO planning and launching.

\section{CONCLUSIONS}

This paper presents a reference model which has the capability to systematically plan and launch VOs. Through this reference it is possible to integrate all the information related with VO planning and launching.

Enterprise Modelling is achieved by creating a VO reference model. This model provides a global view of all the entities involved in planning and launching process.

Based on the case study developed it was shown that the reference model could be easily implemented if the methods and tools required for VO planning and launching are available. However, it is important to generate enough trust among VO members in order to enhance VO creation lead time and there is need to have defined the tools required for VO planning and launching prior to use the reference model in order to only use the required resources. 
VO reference model provides a modular structure for VO methodologies and tools. These modules should develop and implemented for specifics VOs requirements.

Future research activities should be developed in order to validate VO reference model in several virtual enterprises in México and other countries.

VO reference model feasibility has been demonstrated by the results obtained in IECOS operation. By implementing VO reference model in IECOS it was possible to enhance the process planning and launching, the creation of a knowledge repository helps in future project planning and launching decisions.

The methodology proposed by TØlle (2004) provides a good general basis for this work, however is important to consider VO specific requirements to complement planning and launching stages.

In the study case presented in this paper, an object oriented database was used to create a knowledge repository; however, the use of ontology managers should be further analyzed.

\section{ACKNOWLEDGEMENTS}

The authors acknowledge ECOLEAD project (European Collaborative Networked Organizations Leadership Initiative), Baltsoft Corporation, and the "IBM SUR Program" for their funding and support in the development of this research.

\section{REFERENCES}

1. Bernus P., Nemes L. and Schmidt G. Handbook of Enterprise Architectures, Springer, 2003, New York, USA, pp. 22-60

2. Camarinha-matos L.M. and Afsarmanesh H. Collaborative Networked Organizations: a research agenda for emerging business models, Springer, 2004, New York, USA, pp. 7-10

3. Fischer T. and Rehm S., A Cibernetic approach towards knowledge-based coordination of dynamically networked enterprises; Virtual Enterprises and Collaborative Networks: IFIP $5^{\text {th }}$ Working Conference on Virtual Enterprises, Kluwer Academic Publishers, 2004, Toulouse, Fr.

4. Guerra D., A Manufacturing Model to Enable Knowledge Maintenance in decision support system, Phd Dissertation, Mechanical and Manufacturing Engineering, Loughborough, Loughborough University of Technology, 2004, p. 12

5. Jackson, Paul J; Virtual Working: Social and organizational dynamics, Routledge, , London, 21-22, 1999

6. Katzy R.B. and Obozinski V. Designing the Virtual Enterprise, ICE conference, 1999, Den Haag, Netherlands.

7. Leonard, D. and Sensiper, S. The Role of Tacit Knowledge in Group Innovation. California Management Review. Special Issue on Knowledge and the Firm, v. 40, n. 3, p. 112-132, Spring 1998.

8. Saabeel W., Verduijn T.M., Hagdorn L., Kumar K., A Model of Virtual Organisation: A Structure and Process Perspective, Electronic Journal of Organizational Virtualness, 2002, Volume 4

9. Tolle M.; Management and Engineering of Virtual Enterprises, Phd Dissertation: Department of manufacturing engineering and management, Technical University of Denmark, 2004, Denmark, $157-162$

10. Vernadat F.B., Enterprise Modeling and Integration, Chapman \& Hall, London, 1996 